\title{
Confound It!
}

What eludes some, confuses others, and amazes most of the rest of us? It is "confounding," a phenomenon that lies at the root of many apparent paradoxes. Example: I drove a visiting statistician to the airport one day. He proposed not to need a seat belt because the majority of traffic injuries occur within a few miles of one's home, and his home was hundreds of miles away. It was bad humor, but a useful illustration of confounding and how failure to attend to it can have fatal consequences. Danger on the road is not, of course, related to distance from home nearly as much as it is related to time on the road. But because most driving is done near home, one must adjust for driving time, or else. Boston drivers being what they are, local residents might insist he was at greater risk here, but that's a different matter.

Closer to home, professionally speaking, an awareness of confounding is the third stage in a hospital staffs epidemiologic coming of age. The first is acknowledging that there actually have been more than two infections in the hospital during the last five years; the second is realizing that it's important to know both the number of infections and the number of patients at risk. Anyone who has

From the Channing Laboratory, Brigham and Women's Hospital, Harvard Medical School, Boston, Massachusetts.

Address reprint requests to Richard Platt, MD, MS, Channing Laboratory, Brigham and Women's Hospital, Harvard Medical School, Boston, MA $02115-5899$. had the temerity (and the surveillance system) to show conclusively that a particular hospital, service, ward, or surgeon has a higher infection rate than a particular counterpart has surely been informed that such differences are not surprising because people with good numbers avoid taking care of patients with really tough, infection-prone problems. It's such an appealing explanation that the respondent sometimes keeps going. "In fact, our (my) patients would have lots more infections if we (I) didn't do such a good job."

What to do? The most important thing is to understand confounding well enough to know when and when not to worry about it.* Some basic rules are helpful. For instance, one can't just invoke confounding without proposing what the confounder might be. And the groups being compared must be different in the proportion of patients that have the proposed confounder. And the putative confounder has to push the results in the right direction. (If the group with the lower infection rate has a

*Textbooks of epidemiology contain fine definitions of confounding. The important issue is that confounding is a distortion of the relation betueen two factors because both are related to at least one other factor that hasn't been taken into account. Because of confounding, things can appear to be related to one another when they really aren't; or they can seem not to be related when they really are. Confounding isn't the only cause of biased conclusions from data; misclassification and selection biases are other important causes. If you send me a real life example of confounding in the practice of infection control, I'll try to convince the editor to publish a selection of the replies. 
lower proportion of clean surgical procedures and a higher proportion of contaminated ones, then differences in wound class can't be used to explain the difference in infection rates.)

It's also important to identify bona fide risk factors for infection (and thus potential confounders) and to adjust for them when making comparisons. This isn't always easy to do, and the infection control community has come to grips with this slowly. It was an important step to develop and implement a wound classification system that separated clean procedures from contaminated ones so that infection rates could be compared within categories. It was a substantially more sophisticated and useful step for the SENIC (Study of the Efficacy of Nosocomial Infection Control) investigators to extract from a mass of data four easy-to-measure risk factors for postoperative infection. ${ }^{1}$ One benefit of that work is that the rest of us can apply these risk factors and compare our experiences with more assurance than we did previously. This type of investigation and analysis improves both our understanding and our practice. We need much more research of this kind.

Scaling up the infection control research enterprise will provide many opportunities for identifying risk factors that can confound our conclusions unless we pay attention to them, and sometimes for misidentifying them because of other confounders we don't know about or forget to take into account. One of the misses recently emerged when my colleagues and I looked at risk factors for catheter-associated urinary tract infection. ${ }^{2}$ One of the risk factors that had been well established by good prospective surveillance was that catheters were more likely to become infected if they were inserted by LPNs than by $\mathrm{RNs}$, and more likely to become infected if inserted by nurses than by physicians. That's the type of risk factor the infection control community likes to find, because in principle, it's modifiable. It certainly justified putting special effort into in-service education for nursing personnel. But thoughtful nurses commented on occasion that it was an unfair allegation because it fell to nurses almost exclusively to catheterize female patients, often in less than ideal circumstances. In short, they proposed the association was confounded, with nurses catheterizing patients at higher risk of infection for other reasons.

Our analysis suggests the nurses were right and that the infection control literature had done them a disservice. Like others, we found the infection risk was higher for nurses than for physicians. In fact, our data showed infection was 3.6 times more likely to occur if a nurse inserted the catheter than if a physician did. The difference was highly significant $(P<0.0001)$. But when we adjusted for other risk factors that contributed independently to risk of infection, the excess for nurses vanished-completely. Taken together, the other risk factors (patient's sex and others) didn't just partially account for the difference, and they didn't just make an "insignificant" difference. They explained everything.

What's the lesson? Principally, I believe we all need a pretty good grip on confounding, both intuitively, to keep us from misdirecting our energies and those of our associates, and more formally, when we analyze and present the information we collect.

\section{REFERENCES}

1. Haley RW, Culver DH, Morgan WM, et al: Identifying patients at high risk of surgical wound infection: A simple multivariate index of patient susceptibility and wound contamination. Am J Epidemiol 1985; 121:206-215.

2. Platt R, Polk BF, Murdock B, et al: Risk factors for nosocomial urinary tract infection. Am J Epidemiol 1986; 124:977-985. 